\title{
OSCILLATION OF DELAY DYNAMIC EQUATIONS WITH OSCILLATING COEFFICIENTS
}

\author{
BAŞAK KARPUZ AND ÖZKAN ÖCALAN
}

Abstract. In this paper, we study the following delay dynamic equation

$$
x^{\Delta}(t)+p(t) x(\tau(t))=0 \text { for } t \in\left[t_{0}, \infty\right)_{\mathbb{T}},
$$

where $t_{0} \in \mathbb{T}$, sup $\mathbb{T}=\infty, p \in \mathrm{C}_{\mathrm{rd}}\left(\left[t_{0}, \infty\right)_{\mathbb{T}}, \mathbb{R}\right)$ alternates in sign infinitely many times and $\tau \in \mathrm{C}_{\mathrm{rd}}\left(\left[t_{0}, \infty\right)_{\mathbb{T}}, \mathbb{T}\right)$ is a strictly increasing unbounded function satisfying $\tau(t) \leqslant t$ for all $t \in$ $\left[t_{0}, \infty\right)_{\mathbb{T}}$. Our results extend recent results for arbitrary time scales.

Mathematics subject classification (2010): 39A10, 34C10.

Keywords and phrases: oscillation, first-order delay dynamic equations, time scales.

\section{REFERENCES}

[1] R. P. Agarwal, L. Berezansky, E. Braverman and A. Domoshnitsky, Nonoscillation Theory of Functional Differential Equations with Applications, Springer, New York, 2012.

[2] H. AGwo, On the oscillation of first order delay dynamic equations with variable coefficients, Rocky Mountain J. Math., 38, 1 (2008), 1-18, doi:10.1216/RMJ-2008-38-1-1.

[3] M. Bohner And A. Peterson, Dynamic Equations on Time Scales. An Introduction with Applications, Birkhäuser, Boston, 2001.

[4] M. Bohner And A. Peterson, Advances in Dynamic Equations on Time Scales, Birkhäuser, Boston, 2003.

[5] M. Bohner, Some oscillation criteria for first order delay dynamic equations, Far East J. Appl. Math., 18, 3 (2005), 289-304.

[6] M. BOHNER, B. KARPUZ AND Ö. ÖCALAN, Iterated oscillation criteria for delay dynamic equations of first order, Adv. Difference Equ., Art. ID. 58687, 12 pp, (2008), doi:10.1155/2008/458687.

[7] E. BRAVERMAN AND B. KARPUZ, Nonoscillation of first-order dynamic equations with several delays, Adv. Difference Equ., Art. ID. 873459, 22 pp, (2010), doi:10.1155/2010/873459.

[8] E. BRAVERMAN AND B. KARPUZ, On oscillation of differential and difference equations with nonmonotone delays, Appl. Math. Comput., 218, 7 (2011), 3880-3887, doi:10.1016/j.amc.2011.09.035.

[9] S. HiLger, Ein Maßkettenkalkül mit Anwendung auf Zentrumsmannigfaltigkeiten, Ph. D. Thesis, Universität Würzburg, 1988.

[10] B. KARPUZ, Li type oscillation theorem for delay dynamic equations, Math. Methods Appl. Sci., 36, 9 (2013), 993-1002, doi:10.1002/mma.2518.

[11] Y. ŞAhiner AND I. P. STAVRoulakis, Oscillations of first order delay dynamic equations, Dynam. Syst. Appl., 15, 3-4 (2006), 645-656.

[12] X. H. Oscillations of First ORder Delay DYNAMiC EQUations AND S. S. Cheng, An oscillation criterion for linear difference equations with oscillating coefficients, J. Comput. Appl. Math., 132, 2 (2001), 319-329, doi:10.1016/S0377-0427(00)00437-4.

[13] X. H. TANG, Oscillation of first order delay differential equations with oscillating coefficients, Appl. Math. J. Chinese Univ. Ser. B, 15, 3 (2000), 252-258, doi:10.1007/s11766-000-0048-X.

[14] J.S. YU, B. G. Zhang, X.Z. Qian, Oscillations of delay difference equations with oscillating coefficients, J. Math. Anal. Appl., 177, 2 (1993), 432-444, doi:10.1006/jmaa.1993.1267. 
[15] J.S. YU AND X.H. TANG, Sufficient conditions for the oscillation of linear delay difference equations with oscillating coefficients, J. Math. Anal. Appl., 250, 2 (2000), 735-742, doi:10.1006/jmaa.2000.7120.

[16] B. G. Zhang And X. Deng, Oscillation of delay differential equations on time scales, Math. Comput. Model., 36, 11-12 (2002), 1307-1318, doi:10.1016/S0895-7177(02)00278-9. 